\title{
Por uma educação linguística ética- responsável: reflexões sobre práticas discursivas em uma sala de aula de língua inglesa
}

\section{Towards an ethical-responsible linguistic education: reflections on discursive practices in an English language classroom}

Pedro Augusto de Lima Bastos*

Universidade Federal de Goiás - UFG

Goiânia - Goiás / Brasil

Carla Janaina Figueredo**

Universidade Federal de Goiás - UFG

Goiânia - Goiás / Brasil

\begin{abstract}
RESUMO: Estudos recentes em Linguística Aplicada (LA) têm realizado uma aproximação com teorizações bakhtinianas e o ensino-aprendizagem de línguas. Tais estudos concordam que língua é permeada por discursos que dialogam entre si, indo além da noção de língua como um simples sistema rígido de estruturas, que podem ser analisadas em níveis sintáticos, morfológicos, fonéticos etc. Com base nesses pressupostos, pretendemos discutir a partir dos conceitos bakhtinianos de sujeito, dialogismo, ideologia, forças centrípetas/centrífugas, e ato ético, as práticas discursivas de alunos de língua inglesa. Utilizaremos, para isso, recortes de uma aula baseada no vídeo The danger of a single story, de Chimamanda Adichie, que problematiza verdades essencializadas sobre o outro. Com base na discussão entre o material empírico gerado e os pressupostos teóricos, fazemos uma reflexão acerca da importância da formação ética-responsável de alunos/ as com vistas a atender demandas educacionais da contemporaneidade.
\end{abstract}

PALAVRAS-CHAVE: sala de aula de inglês; ética; responsividade; responsabilidade; educação linguística.

ABSTRACT: Recent studies in Applied Linguistics (AL) have developed a dialogue with Bakhtinian theorizations and the teaching and learning of languages. Such studies agree that language is permeated by discourses that

*pedro_itapaci@hotmail.com

** cjfigueredo2@gmail.com 
dialogue with themselves, going beyond the concept of language as a simple rigid system of structures that can be analyzed in syntactic, morphological, and phonetic aspects. Following these premises, we aim to discuss, based on the Bakhtinian concepts of subject, dialogism, ideology, centripetal/centrifugal forces, and ethical act, the discursive practices of English language students. To this end, we make use of parts of a lesson based on the video The danger of a single story, by Chimamanda Adichie, which problematizes essentialized truths about the other. Based on the discussion between the empirical material generated and the theoretical framework, we reflect on the importance of the ethical-responsible formation of students in order to answer contemporary educational demands.

KEYWORDS: English language classroom; ethics; responsivity; responsibility; linguistic education.

\section{Introdução}

Parece ser um fato irrefutável na Linguística Aplicada de que vivemos em um mundo em movimento (MOITA LOPES, 2006a). Mundo este carregado de transformações, fluxos culturais, pessoais, sociais, políticos, econômicos, linguísticos, enfim, tudo que caracteriza nossa sociedade. Fabrício (2006) aponta que essa concepção de mundo em movimento, mesmo que antiga, parece estar mais clara atualmente devido à globalização, ou seja, os processos de globalização têm influenciado a humanidade nas formas de viver e de produzir discursos, linguagens e conhecimentos. No entanto, devemos estar atentos ao fato de que algumas identidades sociais não parecem poder circular neste mundo com tanta facilidade como outras. Teorizações sobre educação como ato responsável (GERALDI, 2013; KRAMER, 2013; OLIVEIRA; SZUNDY, 2014; SZUNDY, 2014), por exemplo, têm sinalizado a importância de formar cidadãos e cidadãs capazes de pensar e agir nesse mundo contemporâneo.

Esse olhar da Linguística Aplicada para o mundo em movimento tem gerado teorizações concernentes ao conceito de língua como uma prática social (FABRÍCIO, 2006, p. 48), cuja concretude nos revela que "ao estudarmos a linguagem estamos estudando a sociedade e a cultura das quais ela é parte constituinte e constitutiva". Os estudos bakhtinianos, por sua vez, reforçam esse mesmo entendimento quando não somente se posicionam em consonância com a noção de língua como prática social, mas, sobretudo, defendem que "a situação social mais imediata e o meio social mais amplo determinam completamente e, por assim dizer, a partir do seu próprio interior, a estrutura da enunciação" (BAKHTIN, 2004, p. 113). Em outras palavras, para Bakhtin (2004), a concepção de discurso ampara- 
se no uso concreto da língua por sujeitos sócio-histórica e culturalmente situados, e, portanto, concretos, os quais se inserem em práticas enunciativas ou práticas discursivas determinadas, acima de tudo, pelo contexto e pelas relações sociais com outros interlocutores. Sustentado, pois, por uma visão sociointeracionista de língua(gem), Bakhtin (2004) acrescenta que tais práticas discursivas são constituídas por uma essência dialógica responsável pelo encontro dos enunciados no plano do sentido, por meio do qual diferentes vozes sociais se materializam, sendo capazes de se relacionar tanto com discursos retrospectivos quanto com discursos prospectivos (FIGUEREDO, 2012).

Considerando os princípios teóricos apresentados anteriormente, cremos que a sala de aula de língua adicional é, também, um lócus de (re) produção de discursos, pois se trata de um contexto social historicamente marcado e movido por enunciados diversos advindos dos interlocutores que a constitui. Sendo assim, apoiados nessa compreensão, objetivamos refletir sobre as práticas discursivas dialógicas presentes em uma aula de língua inglesa planejada a partir do vídeo The danger of a single story e, mais especificamente, como os construtos bakhtinianos de sujeito, ato ético, forças centrípetas/centrífugas e ideologia, além de dialogismo, podem nos ajudar a compreender a importância da formação ética-responsável com vistas a atender as demandas educacionais da contemporaneidade.

Este texto está dividido em cinco seções, as quais estão dispostas na seguinte ordem: 1) a introdução da pesquisa; 2) a fundamentação teórica com os conceitos bakhtinianos de sujeito, ato ético, forças centrípetas/centrifugas, ideologia e dialogismo; 3) a contextualização e a metodologia da pesquisa; 4) a discussão sobre o material empírico gerado à luz dos conceitos bakhtinianos; 5) a reflexão sobre o que Bakhtin tem a dizer aos educadores da língua(gem) com base em nossa interpretação situada das teorizações e do material empírico gerado.

\section{Teorização}

Antes de iniciarmos a discussão, faz-se importante ressaltar que não nos prenderemos às questões polêmicas envolvendo a autoria das obras e dos conceitos desenvolvidos pelo Círculo de Bakhtin. Portanto, durante o texto, referimo-nos aos conceitos como bakhtinianos ou pertencentes ao Círculo de Bakhtin com o intuito de caracterizar a comunidade na qual foram desenvolvidos, mesmo se a indicação da referência for somente Bakhtin ou outro membro do Círculo. 
Decidimos por discutir, primeiramente, o conceito de dialogismo por considerá-lo como basilar para a apresentação dos outros. Para Bakhtin (1997, p. 345-346), trata-se de "uma relação (de sentido) que se estabelece entre enunciados na comunicação verbal. Dois enunciados quaisquer, se justapostos no plano do sentido (não como objeto ou exemplo linguístico), entabularão uma relação dialógica". Em outras palavras, todo e qualquer tipo de enunciação representa uma resposta a enunciados anteriores e que podem, também, antecipar enunciados futuros. As relações dialógicas são, portanto, marcadas por uma profunda originalidade e complexidade na construção dos sentidos, mas que não se limitam às réplicas de um diálogo comum, constituído por perguntas e respostas (BAKHTIN, 1997; 2004).

Sob a perspectiva de Bakhtin e o Círculo, compreendemos que os enunciados encontram-se dispostos em um continuum sem fim da língua(gem), no qual um enunciado é apenas um elo na cadeia enunciativa dialógica das vozes sociais. O importante aqui não é saber o começo e o fim dessa corrente, mas como um enunciado, um dito, se relaciona com outros enunciados, "tendo como referência o todo da interação verbal e não apenas o evento da interação face a face” (FARACO, 2009, p. 65). Isso confirma que a ocorrência do dialogismo não depende de uma similaridade espacial e temporal entre os interlocutores, mas, sim, da presença de uma "confrontação ou convergência de sentidos entre os seus mais diversos pontos de vista e opiniões” (FIGUEREDO, 2012, p. 70).

Tal característica de independência temporal e espacial do dialogismo faz dele um construto muito importante para entender os fluxos de discursos na sociedade contemporânea. Por causa da globalização e dos avanços tecnológicos, discursos podem flutuar de um espaço-tempo para outro com mais facilidade. O Círculo caracteriza essa flutuação de vozes sociais como heteroglossia dialogizada, melhor dizendo, "vozes sociais [que] se entrecruzam continuamente de maneira multiforme, processo em que se vão também formando novas vozes sociais" (FARACO, 2009, p. 58). No entanto, Faraco (2009, p. 68) nos atenta para o fato de que tais processos dialógicos não são em nada consensuais, pois eles podem "resultar tanto a convergência, o acordo, a adesão, o mútuo complemento, a fusão, quanto a divergência, o desacordo, o embate, o questionamento, a recusa”.

Esses enunciados, que circulam por meio do dialogismo, para o Círculo de Bakhtin, são sempre ideológicos (BAKHTIN, 2004). A língua(gem), nesse sentido, é ideologicamente saturada, pois se refere aos diferentes 
pontos de vista que podem ser feitos em seu uso. Dito de outra forma, é "todo o conjunto dos reflexos e das interpretações da realidade social e natural que tem lugar no cérebro do homem e se expressa por meio de palavras [...] ou outras formas sígnicas" (VOLOCHINOV, 1998, p. 107). Vale lembrar que o Círculo não compartilha do significado de ideologia marxista como mascaramento do real, visto que tudo é ideológico. Isso faz com que o sujeito, ao enunciar, possua uma posição avaliativa em relação ao que será enunciado; tudo aquilo que é falado vem de um lugar socialmente e historicamente situado e representa visões de mundo ideologicamente impregnadas, nunca neutras. Nesse sentido, o interlocutor não ocupa uma posição passiva na produção de enunciados (FIGUEREDO, 2012; MOLON; VIANA, 2012).

Molon e Viana (2012) afirmam que apenas a constituição sóciohistórica de sujeitos não caracteriza o signo/enunciado como ideológicos, pois a capacidade de refletir e refratar a língua(gem) ocupa uma posição primordial. Tendo por base sua característica dialógica, “o signo reflete a realidade, por meio da sua propriedade de referenciar-se, de adquirir sentido que ultrapasse suas próprias particularidades" (MOLON; VIANA, 2012, p. 150). Mas, além de sua função de refletir, o signo/enunciado também refrata e, sobre isso, Bakhtin (2004, p. 38, grifos do autor) acrescenta que

[n]enhum signo cultural, quando compreendido e dotado de um sentido, permanece isolado: torna-se parte da unidade da consciência verbalmente constituida. A consciência tem o poder de abordá-lo verbalmente. [...] Toda refração ideológica do ser em processo de formação, seja qual for a natureza de seu material significante, é acompanhada de uma refração ideológica verbal, como fenômeno obrigatoriamente concomitante. A palavra está presente em todos os atos de compreensão e em todos os atos de interpretação.

Isso significa que, ao enunciar, nossa posição avaliativa junto com nossa capacidade de refutar, modificar, distorcer etc., estarão tecendo interpretações diversas e influenciando a constituição ideológica de significados.

Esses enunciados, no entanto, não se encontram numa posição de equipolência, tendo em vista que forças centrippetas e centrifugas regem a movimentação das diferentes vozes sociais. Em outros termos, Bakhtin 
(2004, p. 66) considera que "cada palavra se apresenta como uma arena em miniatura onde se entrecruzam e lutam os valores sociais de orientação contraditória. A palavra revela-se, no momento de sua expressão, como o produto da interação viva das forças sociais", ou seja, é um lugar de enfrentamento em que há a presença do Outro no qual essas forças agem. Segundo Faraco (2013, p. 175), as forças centrípetas trazem para o centro, para o único, ou seja, elas

tentarão impor uma das verdades sociais (a sua) como a verdade; tentarão submeter a heterogeneidade discursiva (controlar a multidão de discursos); monologizar e canonizar (dar a última palavra); tornar o signo monovalente (deter a dispersão semântica); finalizar a dialogização da heteroglossia.

Como afirma Faraco (2013, p. 176), apesar de não desenvolver nenhuma teoria sobre dominação, poder, ou luta de classes, o Círculo de Bakhtin "diz que a classe dominante tenta tornar monovalente o signo". Opondo-se à força centrípeta, a força centrífuga é representada pelo movimento de dentro para fora, atingindo diferentes direções. As forças centrífugas da língua(gem) são consideradas mais dialógicas, pois "corroem continuamente todos os esforços de centralização discursiva" (FARACO, 2013, p. 176), de monologismo. Elas são mais abertas às desestabilizações e circulação de diferentes discursos. É interessante notar que o Círculo não oferece nenhuma perspectiva de extinção de forças centrípetas, mas afirma que o jogo entre essas forças (centrípetas e centrífugas) é infinito e elas sempre agirão continuamente.

Assim sendo, como fica, então, o sujeito nesse emaranhado de enunciações? Sobral (2009a, p. 50-51, grifo do autor) afirma que, para Bakhtin e o Círculo, o sujeito possui três características essenciais, são elas:

1. É dotado de uma constituição psíquica que explica sua identidade relativamente fixada;

2. Traz na constituição de sua condição de sujeito [...] as marcas dos aspectos sociais e históricos de sua vida em sociedade;

3. Age sempre.

No primeiro aspecto, podemos perceber que o sujeito bakhtiniano não é fixo totalmente e, mesmo que sua consciência tenha certa continuidade, 
ele possui determinada fluidez e se modifica nas relações estabelecidas com outros sujeitos. Geraldi (2010, p. 289, grifo do autor) afirma que

o sujeito de Bakhtin é sempre de uma incompletude fundante, $[\ldots]$ e que a demanda de completude - o movimento em direção ao outro - será sempre um movimento que não produz solução, no sentido de que o excedente de visão permanecerá produzindo novos acabamentos a que o $e$ n não tem acesso.

Por conseguinte, o outro possui uma posição imprescindível na constituição do $\ell$, e essa construção se dá pela relação dialógica entre o en e os outros eus, isto é, o sujeito "vai-se constituindo discursivamente, assimilando vozes sociais e, ao mesmo tempo, suas inter-relações dialógicas" (FARACO, 2009, p. 85) no caldeirão de vozes sociais dos outros, que poderão ser suas, caso deseje. No entanto, Geraldi (2010) é enfático ao afirmar que, mesmo com a busca pela completude no outro, o sujeito nunca será completo, ele é sempre inconcluso; sua completude total anularia seu fator intrínseco de mudança constante. Nas palavras de Pires e Sobral (2013, p. 214), "nosso ser está em constante transformação, e cada transformação nos ajuda a sermos mais aquilo que podemos ser a cada momento".

A segunda característica do sujeito bakhtiniano se refere ao que Geraldi (2010) chama de sujeito datado. O autor afirma que há "um entrelaçamento entre passado, presente e futuro que se realizam concretamente num espaço historicizado pelo tempo" (GERALDI, 2010, p. 291). O sujeito é, assim, um ser-evento único que vive no aqui-agora. Geraldi (2010) complementa dizendo que esse atributo do sujeito pode ser visto como uma limitação, mas precisamos lembrar que aquilo que realizamos nesse aqui-agora influenciará outros acontecimentos no futuro. Podemos depreender, ainda neste ponto, outra característica fundamental do sujeito: possuir subjetividades constituídas sócio-historicamente. Pires e Sobral (2013, p. 211) reforçam que "a subjetividade é o que fundamenta nossa percepção de ser humano. É ela que viabiliza nossa identificação com alguns e nosso 'olhar enviesado' para outros; é ela o que funda as identidades”. Isso também ressalta o caráter ideológico do sujeito, visto que suas ações são enviesadas pela sua constituição sócio-histórica. Devido a essas questões, Faraco (2009) nos questiona: se ao dizer que o sujeito enuncia vozes de outros, poderia ele ser isento de sua responsabilidade com o que diz e faz? 
Sobral (2009b) afirma que o grande interesse do Círculo de Bakhtin era criar uma filosofia da língua(gem) com o objetivo de entender o agir humano, se diferenciando dos estudos linguísticos de orientação estruturalista, que entendiam a língua como um sistema abstrato acima dos seres humanos. Bakhtin, então, propõe o "estudo do agir humano no mundo concreto" (SOBRAL, 2009b, p. 24), sendo o "ato de Bakhtin um processo do ato, um produto do ato e um agente (interagente) do ato" (SOBRAL, 2009b, p. 25). Apesar de o Círculo considerar cada ato como irrepetível, singular, e único no espaço-tempo, os atos possuem elementos em comum que os inserem na grande categoria ato. $\mathrm{O}$ agir humano não é aleatório, mas guiado por sua responsabilidade e responsividade, que o transforma em ato ético. Responsabilidade e responsividade se fundem, pois "a ética diz respeito a uma atitude responsiva dos sujeitos frente aos eventos e enunciados únicos, singulares e particulares que os interpelam no mundo concreto das relações e dos embates" (SEVERO, 2013, p. 161). É importante enfatizar que, para Bakhtin e o Círculo, ética não se refere às questões morais do que é certo ou errado, mas, sim, à responsabilidade que o sujeito possui ao deixar "uma 'assinatura' em seu ato"' (SOBRAL, 2009b, p. 30).

A responsividade, por sua vez, diz respeito à ação de responder a algo ou a alguém, a qual nos revela uma condição inevitável do sujeito, pois mesmo quando se recusa a interagir com o outro, o seu simples desejo de negação implica em resposta a esse outro. Por ser um sujeito sócio-histórico, ideológico e cultural, não é possível que ele despreze o mundo ao seu redor, nem tampouco se isente de sua responsabilidade em relação a ele (BAKHTIN, 1997). O ato da resposta é, portanto, acompanhado de um ato responsável que marca sua participação agentiva nas mais diversas esferas da comunicação.

O termo responsibilidade é muito utilizado para se referir ao caráter responsivo e responsável do sujeito. De acordo com Sobral (2008), a perspectiva bakhtiniana fala da necessidade de sair de si e de se aproximar do outro, isto é, é necessário que nos coloquemos no lugar do outro antes de tomarmos decisões, falarmos ou agirmos. Dessa forma, "Bakhtin exige coerentemente de cada sujeito a responsabilidade por seus atos e obrigações éticas com relação aos outros sujeitos" (SOBRAL, 2008, p. 229). Em suma, ser ético para o Círculo é se colocar no lugar do outro no aqui-agora único, é também saber que deixamos nossa autoria nos atos que realizamos e nos enunciados que enunciamos e compreender que todo enunciado exige uma resposta. 
Podemos observar, portanto, que as teorizações do Círculo vão muito além de linguísticas. Elas propõem uma teoria mais abrangente, que visa analisar os atos do sujeito em relação com suas língua(gens) e a sociedade (SOBRAL, 2009b). Na próxima seção, nossa pesquisa será contextualizada.

\section{Contextualização}

Nosso estudo enquadra-se em uma abordagem qualitativa de base interpretativista pelo fato de compreender o significado como algo "socialmente construído pelos indivíduos em interação com seus mundos" (MERRIAM, 2002, p. 3). Tendo em vista que nosso objetivo principal é abordar as práticas discursivas e dialógicas na sala de aula de Inglês, "entender os significados que as pessoas têm construído sobre seus mundos e experiências” (MERRIAM, 2002, p. 4-5) representa, antes de tudo, o papel principal do pesquisador qualitativo frente a uma investigação que prioriza as palavras e os sentidos atribuídos a elas.

Adotamos as premissas do estudo de caso visto que, primeiramente, se tratou de uma pesquisa realizada em um curto espaço de tempo, e, em segundo lugar, se concentrou em uma única unidade de análise pertencente a um contexto maior. Em outras palavras, o material empírico gerado é proveniente de uma aula do curso Conversação e Pronúncia em Lingua Inglesa, de 16 horas, do programa Idiomas sem Fronteiras, a qual foi ministrada pelo primeiro autor deste texto. A título de representação, ao longo da discussão dos dados, ele será identificado como professor regente.

Quanto ao Idiomas sem Fronteiras, trata-se de um projeto do Ministério da Educação que visa ensinar línguas adicionais para a comunidade universitária de universidades públicas brasileiras. Os cursos são oferecidos gratuitamente na tentativa de preparar as universidades públicas para a internacionalização. Em nossa pesquisa, três alunos e três alunas estavam presentes na aula em que os dados foram gerados. Seus nomes verdadeiros foram substituídos por pseudônimos escolhido por eles/as. Quanto ao curso Conversação e Pronúncia em Lingua Inglesa, sua configuração foi marcada por aulas fundamentadas em perspectivas críticas para o ensino de línguas (PENNYCOOK, 1999; 2001; PESSOA; URZÊDA-FREITAS, 2012), as quais objetivavam conduzir os/as alunos/as a discussões de temas tais como estereótipos, raça/racismo, entre outros, por meio de vídeos e textos autênticos. Nossa escolha pelo material empírico discutido neste texto se deu pelo fato de as práticas discursivas dos/as participantes terem ocorrido com 
maior fluidez ao longo da aula selecionada, ou seja, a partir das discussões com base no vídeo, os/as alunos/as produziram discursos diferentes no início e no fim da aula.

A atividade que discutimos aqui tinha como foco promover reflexões acerca de ações pautadas na estereotipificação do outro que se difere de nós, questões essas discutidas por Chimamanda Adichie (2009) em seu vídeo The danger of a single story. Para a obtenção dos dados, contamos com dois instrumentos, a saber: um questionário, cujo único objetivo foi definir o perfil de nossos/as participantes, garantindo a eles/as a sua representatividade na pesquisa; e a gravação em áudio da aula ministrada. A tabela abaixo foi criada para apresentar nossos/as participantes ao leitor:

TABELA 1 - Perfil dos/as alunos/as participantes da pesquisa

\begin{tabular}{l|c|l|l|l|l}
\hline $\begin{array}{c}\text { Nome } \\
\text { Fictício }\end{array}$ & Idade & \multicolumn{1}{|c|}{ Raça } & Escolaridade & \multicolumn{1}{|c}{ Profissão } & $\begin{array}{c}\text { Renda (em } \\
\text { salários } \\
\text { mínimos) }\end{array}$ \\
\hline Rachel Earl & 25 & Negra & Superior (cursando) & Professora & De 2 a 4 \\
\hline Aluno 6 & 34 & Branco & Superior & Professor & De 10 a 20 \\
\hline Orion & 43 & Branco & Superior & Servidor Público & De 4 a 10 \\
\hline João & 24 & Pardo & Superior (cursando) & Analista de Sistemas & De 4 a 10 \\
\hline Karina & 31 & Branca & Superior & Psicóloga & De 4 a 10 \\
\hline Angelina & 21 & Não declarou & Superior (cursando) & Estudante & Até 2 \\
\hline
\end{tabular}

Fonte: Elaborado pelos autores, 2016.

Nesta pesquisa, além de refletirmos sobre as práticas discursivas presentes em uma aula de inglês, tentaremos compreender a importância da formação ética-responsável com o intuito de atender as demandas educacionais da contemporaneidade, com base nos conceitos bakhtinianos de sujeito, ato ético, forças centrípetas/centrífugas, ideologia e dialogismo. Na próxima seção, o material empírico será relacionado com os conceitos mencionados anteriormente.

\footnotetext{
${ }^{1}$ Durante a geração do material empírico, o valor corrente do salário mínimo era de $\mathrm{R} \$ 880,00$.
} 


\section{Discussão}

O primeiro trecho apresentado é parte de uma atividade em que o professor regente entregou vários nomes de países para os/as alunos/as e, a partir daí, eles/as deveriam dizer as primeiras coisas que pensassem sobre cada país. Essa tarefa era uma preparação para a atividade com o vídeo The danger of a single story. Segue o Trecho 1:

14) Teacher: So, what comes to your mind when you see the word India? ${ }^{2}$

15) Rachel Earl: Dirty country, stinky people.

16) Teacher: Dirty and stinky? Why?

17) Rachel Earl: When an Indian guy came here to present a dissertation, it's not that he is stinky, but the smell is different. I think the... I don't know how to say, but it's stinky.

18) Teacher: But are all Indians like this?

19) Rachel Earl: I don't know, but my teacher went to India and she said yes. I don't know the rich people, but all the most people yes, because there is no saneamento básico.

20) Orion: Not one people, just one billion. (risos)

21) Rachel Earl: Ahh, the cows, the goddess of Indians.

22) Karina: Taj Mahal.

23) Teacher: What else?

24) João: Curry.

25) Teacher: Curry?

26) João: I hate. (risos)

27) Orion: Nile river.

28) Teacher: Nile river?

29) Some students: Nile river.

30) Teacher: Ohhh, but it's in Egypt, isn't it?

31) Rachel Earl: Ahh, yeah, it's Ganges river.

32) Aluno 6: Nobel Prize winners. There are a lot of Nobel prize winners.

33) Teacher: From India? Really?

34) Orion: Technology.

35) Teacher: Really? I didn't know that.

36) Angelina: Chandrasekhar was the name of the physicist that won a Nobel prize from India.

\footnotetext{
${ }^{2}$ A numeração dos turnos segue a ordem dos excertos da transcrição original.
} 
37) Aluno 6: They are crazy about Nobel prize.

38) Rachel Earl: When I see India, I think of Sense8.

39) Teacher: Sense8 the TV series?

40) Some students: Yeah.

41) Angelina: Namaste. Because I have a tattoo in Sanskrit.

42) Teacher: Interesting. Have you all watched Sense8?

43) Students: No, yes.

44) Teacher: What is the image from India that they show?

45) Rachel Earl: The colorful, the weddings, and...

46) Angelina: Tradition of the culture.

47) João: This beautiful tradition for weddings. I don't know if the bride is happy about it. (risos)

48) Rachel Earl: They marry early, and they don't know. Only in marriage they know each other.

49) Teacher: I see.

50) Angelina: The conflict between religion and the new ideas of the new generation.

51) Teacher: In Sense8?

52) Angelina: Yeah.

No excerto anterior, podemos observar como a sala de aula de línguas é preenchida com diferentes vozes sociais, ou seja, heteroglóssica, na perspectiva de Bakhtin e o Círculo. O país debatido era a Índia, e os/as alunos/as pareciam possuir muitas informações a respeito. Vemos na fala de Rachel Earl que ela se apoia no fato de ter encontrado um indiano e nas experiências de uma professora ao afirmar que todos/as os/as indianos/as possuem mal cheiro. Isso vai de encontro com o que Chimamanda Adichie (2009, grifo nosso) diz sobre estereótipos: “o problema com estereótipos, não é que eles são incorretos, mas que eles são incompletos. Eles fazem uma bistória se transformar em uma única história".

Nas falas de Aluno 6 e de Angelina, observamos como a noção de sujeito datado e ideológico do Círculo de Bakhtin se encaixa aqui. O Aluno 6 é professor universitário de biologia, enquanto Angelina é aluna de Engenharia Física, e podemos ver que seus enunciados sobre a Índia são, de certa forma, diferentes dos outros por causa das suas experiências e vivências. Ao mencionar sobre Prêmio Nobel e o físico Subrahmanyan Chandrasekhar, esses alunos marcam seus enunciados com seus posicionamentos ideológicos, ou seja, seus "universo[s] da produção imaterial humana" (FARACO, 2009, p. 47). 
Do excerto 38 ao 52, há uma nova voz sendo introduzida. Os/as alunos/as João, Rachel Earl e Angelina discutem sobre a série Sense8, que possui uma personagem indiana. Na série, há uma personagem que está para se casar com um homem que ela não ama. Ramasubramanian (2005, p. 243) afirma que as "imagens de mídia de massa possuem um papel inquestionável na influência das atitudes de pessoas sobre grupos com menor poder, especialmente quando apresentados em modos muito reais como em filmes". Essas imagens de mídia de massa, a nosso ver, representam, muitas vezes, as forças centrípetas ou monologizadoras condutoras da circulação de enunciados que essencializam a constituição dos sujeitos. Ramasubramanian (2005, p. 259) analisa como a cultura indiana é representada em produções cinematográficas ocidentais e descobre que "um padrão definitivo de imagens estereotipadas da Índia aparece em filmes feitos no Ocidente" e que esses padrões podem "modelar a consciência coletiva das atitudes negativas e preconceituosas da audiência Ocidental para com a Índia”. Esse fato, por sua vez, centraliza as construções de significados que fazemos, destituindonos da possibilidade de diálogos com diferentes sentidos, o que consolida ainda mais a força centrípeta.

As palavras de Faraco (2013, p. 176), ao dizer que "a classe dominante tenta tornar monovalente o signo - que é, no entanto, sempre polivalente -, imprimindo-lhe com esse gesto, um caráter de deformação do ser a que remete o signo" parecem ressoar o que Ramasubramanian diz sobre representações indianas em filmes ocidentais. No excerto anterior, e a partir da discussão de Ramasubramanian (2005), podemos ver, também, como as forças centrípetas da produção da série Sense 8 atuaram nessa aula específica ao reproduzir o status da mulher na questão do casamento arranjado na Índia, enxergado a partir do ponto de vista ocidental. Com isso, podemos afirmar que a sala de aula de línguas pode ser um espaço onde discursos regulados por forças centrípetas e monologizantes são reproduzidos nos enunciados $\mathrm{dos} / \mathrm{as}$ alunos/as.

O Trecho 2 se refere ao segundo momento da aula, quando o professor regente e seus/as alunos/as discutiram uma parte do vídeo:

190) Teacher: What type of stories did she read?

191) Students: American and British books.

192) Teacher: And how were the characters portrayed?

193) Students: They played in the snow, were white, blue eyed, eat apples, drunk. 
194) Teacher: What did they drink?

195) Students: Ginger beer.

$[\ldots]$

201) Teacher: And what is the relationship between what she reads and writes?

202) Aluno 6: She reproduced what she was reading... exactly.

203) Teacher: And was it [what she read] very similar to her reality?

204) Student: No.

205) Teacher: What was her reality compared to what she read?

206) Rachel Earl: When they ate apples, she ate mangos. The... about the weather, they had snow and she didn't discuss the weather.

207) Teacher: Why not?

208) Students: All the time was hot. [...]

221) Teacher: And what happened after she started reading African books?

222) Rachel Earl: She recognized her.

223) Teacher: She recognized what?

224) Rachel Earl: In the book.

225) Teacher: Herself?

226) Rachel Earl: Yeah, herself.

227) João: She said she had a mental shift and that she finally could read books that she could identify to because there were stories that she knows about with people like her.

228) Teacher: And what are single stories? What is your definition of single stories that you could understand from the video?

229) Rachel Earl: It's difficult to say this.

230) João: A single story is just one point of view someone has about something.

231) Teacher: What else?

232) Orion: You see just one side of the story.

233) Teacher: $[\ldots]$ So what is the importance the other has in ourselves? What is the importance you have in my story? What is the importance I have in your story?

234) Angelina: I think it's another idea.

235) Orion: Second opinion.

$[\ldots]$

250) Aluno 6: 'Cause if you, if your opinions, our opinions are based only in one ideology is dangerous. You don't have an ideology to compare, to think about. 


\section{$[\ldots]$}

253) Teacher: [...] So her opinion, her worldview she had when she was a kid. Was it about the place she lived, something close to her or something distant?

254) Students: Distant.

255) Teacher: That came from?

256) Students: American and British books.

257) Teacher: So how do you think this influences herself?

258) Karina: When she started reading African books, I think she realized the territory was close to her.

259) Indistinct conversation

260) Aluno 6: That she could be part of the stories.

Nesse trecho, percebe-se como os/as alunos/as notaram as influências das forças centrípetas e monologizadoras na formação do sujeito, aqui relacionado com o sujeito bakhtiniano, a partir do conteúdo do vídeo e dos questionamentos do professor regente. No vídeo, Chimamanda, uma nigeriana, afirma que lia apenas livros europeus e americanos quando criança. Como consequência, sua escrita era influenciada pelo que lia. Dos trechos 190 ao 208, com o apoio do vídeo, os/as alunos/as perceberam como "a globalização capitalista pode acarretar numa neocolonização na forma de [...] exploração de trabalho humano físico, cultural/semiótico numa escala muito maior do que no século XIX" (LIN; LUK, 2005, p. 78-79). Devido às novas tecnologias e facilidades na transportação de bens, ideais eurocêntricos e americanizados podem ser (re)produzidos e circulados de forma muito mais fácil e maciça do que anteriormente. É o que acontece tanto na história de Chimamanda, ao ter um padrão cultural imposto, quanto no Trecho 1, quando os/as alunos/as acabam criando imagens generalizadoras do(s) outro(s) por meio da produção audiovisual ocidental.

A leitura de práticas mais localizadas proporcionou, como afirma Chimamanda (2009), "uma mudança mental" na vida da autora. Ela percebeu que sua identidade também poderia estar representada em livros, os quais são fontes de conhecimento, assim como as identidades de americanos e europeus. Sendo a colonialidade os resquícios do colonialismo, acreditamos que essa leitura localizada de Chimamanda seria uma tentativa de decolonizar o pensamento, ou seja, um trabalho voltado à "visão da vida humana que não é dependente ou estruturada pela imposição forçada de um ideal de sociedade sob aqueles que diferem" (MIGNOLO, 2007, 
p. 459, tradução nossa). Essa decolonização seria, a nosso ver, uma abertura maior para que enunciados diversos pudessem circular mais igualmente, favorecendo o processo de heteroglossia dialogizada, em que "vozes sociais se entrecruzam continuamente de maneira multiforme, processo em que se vão também formando novas vozes sociais" (FARACO, 2009, p. 58) e, consequentemente, propagando práticas discursivas outras por meio de forças centrífugas.

No restante do Trecho 2, encorajados/as pelas perguntas do professor regente, os/as alunos/as são levados a refletir sobre o conceito de single stories e da importância do outro na formação do eu. As respostas dos/as alunos/ as sobre o conceito de single stories podem ser relacionadas aos conceitos de forças centrípetas e forças centrífugas. A partir da discussão sobre a importância do outro, os/as alunos/as perceberam o inacabamento do sujeito (bakhtiniano) e sua capacidade de estar sempre em transformação. Além disso, como enfatizado pelo Aluno 6, é muito importante que esse sujeito conheça essas várias verdades (FARACO, 2009) que estão em circulação pela língua(gem). Mesmo sem falar de estudos bakhtinianos na sala de aula, percebemos que o Aluno 6 compartilha do conceito bakhtiniano de ideologia, pois, para ele, nossas opiniões devem ser produzidas através dos diferentes pontos de vista transmitidos pela língua(gem) ideologicamente saturada.

Vamos ao Trecho 3:

453) Teacher: $[\ldots]$ Because some people create their point of view and they think it's their only one [which is right]. So how can we deal with this?

454) Karina: I think add the word too. For example, like Africa. Africa is a big continent that has this, but this too, but this too. Add the word too. Do you understand? Brazil, Brazil is Carnival, too. Is. Is Carnival. Is a part of, but not..

455) João: It's not like the only thing.

456) Karina: Yes. Yes. Because the world is so big and have a lot of things and people, not close in one part.

457) Angelina: [indistinct conversation] listen to other parts too and later make a puzzle.

458) Teacher: But don't make the puzzle [...] as the only truth.

459) João: I think what we are trying to say is not taking the part as the whole, so... Of course that it's part of it. Carnival is a part of Brazilian culture, but... 
460) Students: Not the only one.

461) João: Yes, and even like in several states they celebrate Carnival in different ways, so... Of course we have like the Rio standard Carnival, we could say, but like, in the northeast, they do in such a different way and it's like, most people don't have that picture of it.

462) Teacher: So we even have differences between the category of Carnival.

463) Students: Yes.

464) João: Like, it's the same holiday, but everyone, kind of, [celebrates it] in different ways.

465) Angelina: There are single stories inside the single stories.

466) João: It's endless.

O Trecho 3 é parte do último momento da aula. Percebemos, então, como os/as alunos/as se apropriaram da característica inacabada, incompleta e sempre em mudança dos enunciados e dos sujeitos. Além disso, acreditamos que os/as alunos/as também agiram eticamente ao não aceitar que o outro deve ser essencializado. Responsibilidade, aspecto fundamental na constituição do sujeito bakhtiniano, é algo que faz parte das práticas discursivas realizadas ao final da aula. A aluna Karina utiliza a língua(gem) como uma ferramenta para inacabar seus discursos sobre o(s) outro(s) ao desestabilizar afirmações generalizadas acrescentando o advérbio too ("também", em português) em sua fala. No excerto 456, ela considera impossível estabilizar outras identidades, pois, devido à diversidade do mundo, é impossível afirmar de modo geral o que o outro é.

João, por sua vez, traz a reflexão de Karina para o contexto brasileiro desestabilizando os significados construídos em torno do carnaval brasileiro, afirmando que o feriado possui diferentes significados culturais e modos de celebração dentro do Brasil, ampliando, assim, a noção de que há apenas uma forma de celebrar o carnaval. O problema em estabilizar a imagem do Brasil como o país do carnaval não está no fato de isso ser uma inverdade; mas, sim, no fato de essa imagem ser "incompleta" (ADICHIE, 2009). Além disso, João e Angelina ainda discutem sobre a característica inacabada da produção e da mudança de significados. João nos confronta ao dizer que, mesmo quando tentamos desestabilizar um significado, infelizmente, ainda falhamos. 
Por fim, concluímos que os/as alunos/as, ao final da aula, revelaram uma postura ética em suas práticas discursivas essencialmente dialógicas, principalmente quando compreenderam que suas (enunci)ações exercem um importante papel na constituição dos outros enquanto sujeitos. Sua busca em compreender o outro com base em diferentes ideologias que o constituem sinaliza não somente sua tentativa de desconstruir a imagem do sujeito uniforme e essencializado, como também alia-se à perspectiva bakhtiniana de responsividade, visto que "toda compreensão da palavra viva, do enunciado vivo, é de natureza ativamente responsiva [...]; toda compreensão é prenhe de resposta, e nessa ou naquela forma a gera obrigatoriamente: o ouvinte se torna falante" (BAKHTIN, 1997, p. 171). Dito de outra forma, os / as alunos/as não se limitaram ao simples ato da resposta requerido pelo professor regente, mas, sobretudo, perceberam que o ato ético direcionado ao outro implica em sua responsividade e responsabilidade em relação a ele, atributos pelos quais ele imprime sua assinatura pela força de seus enunciados e que, ao mesmo tempo, são sensivelmente afetados e transformados pelas construções discursivas que procedem desse outro.

\section{Conclusão}

Em seu texto, Geraldi (2013) conta uma breve história sobre Bakhtin ter falado ou não sobre educação em seus textos. $\mathrm{O}$ autor questiona o leitor se a utilização de conceitos bakhtinianos em pesquisas sobre ensino seria uma usurpação, visto que o Círculo nada havia escrito para a educação. No entanto, Geraldi (2013, p. 12) afirma que há uma forte preocupação, nos textos de Bakhtin, "com a formação dos homens que a nós sobreviverão, [e isso é uma] questão típica com que lida a educação”. Sendo assim, como afirmar que Bakhtin e educação não podem se encontrar para dialogar?

Neste trabalho, objetivamos trazer os conceitos bakhtinianos de dialogismo, ato ético, ideologia, forças centrípetas/centrifugas e sujeito, para compreender a importância da formação ética-responsável com vistas a atender as demandas educacionais do mundo contemporâneo. Utilizamos um recorte de uma aula de inglês baseada no vídeo The danger of a single story com o intuito de problematizar noções estabilizadas sobre o outro. Podemos observar, a partir do material empírico, como a sala de aula de línguas é um ambiente constitutivamente dialógico, onde há o encontro de vozes sociais diversas, que questionam e complementam umas às outras. Como afirma Figueredo (2012, p. 85), "é preciso saber lidar com as inúmeras identidades 
envolvidas nesse contexto, cuja maior característica é a instabilidade, isto é, a fluidez contínua que garante ao indivíduo deslizar espontaneamente entre uma forma de se representar e outra". Compreendendo a sala de aula dessa forma, podemos ver o que os conceitos bakhtinianos explicitados neste texto podem nos dizer ainda mais sobre a educação linguística.

Para lidar com essa fluidez contínua no mundo contemporâneo, tão destacada por pesquisadores da Linguística Aplicada (FABRÍCIO, 2006; FIGUEREDO, 2012; MOITA LOPES, 2006a), acreditamos que uma educação ética-responsável deve se comprometer com a constante (re)formulação de práticas discursivas, de forma que não seja negada às identidades marginalizadas a fluidez presente no mundo globalizado. Moita Lopes (2006b, p. 87) critica a ótica ocidentalista na produção de conhecimento por estar preocupada "com quem é o sujeito inscrito nela", excluindo, assim, aqueles inscritos na margem da sociedade por apresentarem diferenças que não se enquadram no padrão modernista-ocidentalista de sujeito. Portanto, a grande questão de uma educação ética-responsável para a contemporaneidade, como o material empírico nos mostra, estaria em não essencializar o outro que é diferente. Em termos bakhtinianos, por considerarmos o mundo fluido e preenchido por discursos que se movem, modificam e são modificados, essencializar seria monologizar, dar a palavra final autoritária sobre um sujeito datado, incompleto e que está sempre em transformação.

Por fim, desestabilizar e desessencializar discursos se tornam tarefas necessárias caso desejemos repensar novas formas de educação linguística e, consequentemente, de viver, pois é no embate e na desestabilização que podemos transformar e reinventar a vida social com a "exclusão de significados que causem sofrimento humano ou significados que façam mal aos outros" (MOITA LOPES, 2006b, p. 103). É, pois, no ato ético, movido por respostas ideologicamente impregnadas e por posturas responsáveis ao outro, que concedemos espaço ao diálogo e ao valor das diferentes vozes sociais que o compõem.

\section{Referências}

ADICHIE, C. N. The danger of a single story. TED: Ideas worth spreading, New York, 2009. Disponível em: < https://goo.gl/Pebczm>. Acesso em: 31 jan. 2017. BAKHTIN, M. M. Estética da criação verbal. São Paulo: Martins Fontes, 1997. BAKHTIN, M. M. Marxismo e filosofia da linguagem. São Paulo: Hucitec, 2004. 
FABRÍCIO, B. F. Linguística aplicada como espaço de desaprendizagem: redescrições em curso. In: MOITA LOPES, L. P. Por uma linguística aplicada indisciplinar. São Paulo: Parábola, 2006. p. 45-66.

FARACO, C. A. A ideologia no/do Círculo de Bakhtin. In: PAULA, L.; STAFUZZA, G. (Org.). Circulo de Bakbtin: pensamento interacional. Campinas: Mercado de Letras, 2013. p. 167-182.

FARACO, C. A. Criação ideológica e dialogismo. In: FARACO, C. A. Linguagem e diálogo: as ideias linguísticas do Círculo de Bakhtin. São Paulo: Parábola Editorial, 2009. p. 45-97.

FIGUEREDO, C. J. A alteridade constitutiva em aulas de inglês como línguacultura estrangeria: a perspectiva do princípio dialógico bakhtiniano. Bakbtiniana: Revista de Estudos do Discurso, São Paulo, v. 7, n. 1, p. 68-87, 2012. DOI: http:/ / dx.doi. org/10.1590/S2176-45732012000100005

GERALDI, J. W. Bakhtin tudo ou nada diz aos educadores: os educadores podem dizer muito com Bakhtin. In: FREITAS, M. T. A. (Org.). Educação, arte e vida em Bakbtin. Belo Horizonte: Autêntica, 2013. p. 11-28.

GERALDI, J. W. Sobre a questão do sujeito. In: PAULA, L.; STAFUZZA, G. (Org.). Círculo de Bakbtin: teoria inclassificável. Campinas: Mercado de Letras, 2010. p. 279-292.

KRAMER, S. A educação como resposta responsável: apontamentos sobre o outro como prioridade. In: FREITAS, M. T. A. Educação, arte e vida em Bakbtin. Belo Horizonte: Autêntica, 2013. p. 29-46.

LIN, A. M. Y.; LUK, J. C. M. Local creativity in the face of global domination: insights of Bakhtin for teaching English for dialogic communication. In: HALL, J. K.; VITANOVA, G.; MARCHENKOVA, L. (Org.). Dialogue with Bakbtin on second and foreign language learning: new perspectives. Mahwah, NJ: Lawrence Erlbaum Associates, 2005. p. 77-98.

MERRIAM, S. Introduction to qualitative research. In: MERRIAM, S. Qualitative research in practice: examples for discussion and analysis. San Francisco: Jossey-Bass, 2002. p. 3-17.

MIGNOLO, W. D. Delinking: the rhetoric of modernity, the logic of coloniality and the grammar of de-coloniality. Cultural Studies, Thousand Oaks, v. 21, n. 2, p. 449-514, 2007. DOI: https://doi.org/10.1080/09502380601162647

MOITA LOPES, L. P. Linguística aplicada e a vida contemporânea: problematização dos construtos que têm orientado a pesquisa. In: MOITA LOPES, L. P. Por uma linguística aplicada indisciplinar. São Paulo: Parábola, 2006a. p. 85-108. 
MOITA LOPES, L. P. Uma linguística aplicada mestiça e ideológica: interrogando o campo como linguista aplicado. In: MOITA LOPES, L. P. Por uma linguística aplicada indisciplinar. São Paulo: Parábola, 2006b. p. 13-44.

MOLON, N. D.; VIANNA, R. O Círculo de Bakhtin e a Linguística Aplicada. Bakbtiniana: Revista de Estudos do Discurso, São Paulo, v. 7, n. 2, p. 142-165, 2012. DOI: http://dx.doi.org/10.1590/S2176-45732012000200010

OLIVEIRA, M. B. F.; SZUNDY, P. T. C. Práticas de multiletramentos na escola: por uma educação responsiva à contemporaneidade. Bakbtiniana: Revista de Estudos do Discurso, São Paulo, v. 9, n. 2. p. 184-205, 2014. DOI: https://doi.org/10.1590/ S2176-45732014000200012

PENNYCOOK, A. Introduction: critical approaches to TESOL. TESOL Quarterly, Wiley Online Library, v. 33, n. 3, p. 329-348, 1999. DOI: https://doi. org/10.2307/3587668

PENNYCOOK, A. Critical applied linguistics: a critical introduction. Mahwah, NJ: Lawrence Erlbaum Associates, 2001.

PESSOA, R.; URZÊDA-FREITAS, M. Challenges in critical language teaching. TESOL Quartely, Wiley Online Library, v. 46, n. 4, p. 753-776, dez. 2012. DOI: https://doi.org/10.1002/tesq.46

PIRES, V. L.; SOBRAL, A. Implicações do estatuto ontológico do sujeito na teoria discursiva do Círculo Bakhtin, Medvedev, Voloshínov. Bakhtiniana: Revista de Estudos do Discurso, São Paulo, v. 8, n. 1, p. 205-219, 2013. DOI: http://dx.doi.org/10.1590/ S2176-45732013000100013

RAMASUBRAMANIAN, S. A content analysis of the portrayal of India in films produced in the West. Howard Journal of Communications, Abingdon, v. 16, n. 4, p. 243-265, 2005. DOI: https://doi.org/10.1080/10646170500326533

SEVERO, C. G. Bakhtin e Foucault: apostando em um diálogo. In: PAULA, L.; STAFUZZA, G. (Org.). Círculo de Bakbtin: pensamento interacional. Campinas: Mercado de Letras, 2013. p. 143-166.

SOBRAL, A. O ato "responsível", ou ato ético, em Bakhtin, e a centralidade do agente. Signum: Estudos da Linguagem, Londrina, v. 11, n. 1, p. 219-235, 2008. DOI: https://doi.org/10.5433/2237-4876.2008v11n1p219

SOBRAL, A. A concepção de sujeito do Círculo. In: SOBRAL, A. Do dialogismo ao gênero: as bases do pensamento do círculo de Bakhtin. Campinas: Mercado de Letras, 2009a. p. 47-60.

SOBRAL, A. Dialogismo e interação. In: SOBRAL. A. Do dialogismo ao gênero: as bases do pensamento do círculo de Bakhtin. Campinas: Mercado de Letras, 2009b. p. 21-46. 
SZUNDY, P. T. C. Educação como um ato responsável: a formação de professores de linguagens à luz da filosofia da linguagem do Círculo de Bakhtin. Trabalhos em Linguistica Aplicada, Campinas, v. 53, n. 1, p. 13-32, 2014. http://dx.doi. org/10.1590/S0103-18132014000100002

VOLOCHINOV, V. N. Que é linguagem. In: PONZIO, A. (Ed.). La revolución bajtiniana: el pensamiento de Bajtín y la ideologia contemporânea. Madrid: Cátedra, 1998.

Data de submissão: 31/07/2017. Data de aprovação: 01/11/2017. 